\title{
A apropriação da escrita do Português pelo surdo
}

\section{The appropriation of Portuguese writing by the deaf}

\section{La apropiación de escritura Portuguesa por sordos}

\author{
iD (9) Flavia Botelho Borges \\ Universidade Federal de Mato Grosso (UFMT), Cuiabá, Mato Grosso, Brasil. \\ E-mail: flavia2b@gmail.com \\ iD 9 Larrisa dos Anjos \\ Universidade Federal de Mato Grosso (UFMT), Cuiabá, Mato Grosso, Brasil. \\ E-mail: larissaruthanjos@yahoo.com.br
}

\begin{abstract}
Resumo: Este artigo pretende compreender a apropriação de Língua Portuguesa (LP) escrita como segunda língua (L2) por alunos surdos matriculados no oitavo ano do Ensino Fundamental no CEAADA, instituição pública de ensino de Cuiabá, Mato Grosso. Para tanto, objetiva analisar conjuntos de atividades escritas a partir de quatro gêneros textuais, mediante acompanhamento e participação de aulas ministradas de LP, constituindo uma pesquisa de cunho qualitativo do tipo estudo de caso e pesquisa-ação. A análise revelou que esses aprendizes são capazes de se apropriarem da LP escrita sem o intermédio da oralidade, entretanto, deparam-se com algumas dificuldades no nível estrutural da sentença e de compreensão.
\end{abstract}

Palavras-chave: Surdo. Apropriação da Escrita. Língua Portuguesa como Segunda Língua. Educação Bilíngue.

Abstract: This article aims to understand the appropriation of Portuguese written Language (LP) as a second language (L2) by deaf 
students enrolled in the eighth year of Elementary Education at CEAADA, a public educational institution in Cuiabá, Mato Grosso. To this end, it aims to analyze sets of activities written from four textual genres, through monitoring and participation in classes taught by LP, constituting a qualitative research such as case study and action research. The analysis revealed that these learners can appropriate written LP without the use of orality, however, they face some difficulties at the structural level of the sentence and comprehension.

Keywords: Deaf. Appropriation of Writing. Portuguese as a Second Language. Bilingual Education.

Resumen: Este artículo tiene como objetivo comprender la apropiación de la Lengua Portuguesa (LP) escrita como segunda lengua (L2) por estudiantes sordos matriculados en el octavo año de Educación Primaria en CEAADA, una institución educativa pública en Cuiabá, Mato Grosso. Para ello, se pretende analizar conjuntos de actividades escritas a partir de cuatro géneros textuales, a través del seguimiento y participación en las clases impartidas por LP, constituyendo una investigación cualitativa del tipo de estudio de caso e investigación acción. El análisis reveló que estos aprendices son capaces de apropiarse del LP escrito sin el uso de la oralidad, sin embargo, enfrentan algunas dificultades en el nivel estructural de la oración y la comprensión.

Palabras clave: Sordo. Apropiación de la escritura. Portugués como Segundo Idioma. Educación Bilingue.

Submetido em 26 de fevereiro de 2021.

Aceito em 25 de maio de 2021.

Publicado em 17 de novembro de 2021. 


\section{Introdução}

De acordo com a Federação Mundial dos Surdos (WFD, 2003), $80 \%$ dos surdos de todo o mundo têm baixa escolaridade, são analfabetos ou semialfabetizados. E, no Brasil, a situação não é diferente, já que grande parte dos surdos não tem uma boa compreensão do português, ou seja, não entende ou tem dificuldades para ler e escrever. Um grande número deles não tem acesso a práticas de letramento significativas que propiciem o domínio da língua escrita, muitas vezes devido ao "preconceito e ignorância de muitos educadores que, em uma atitude de resistência à inclusão, negam-se a incorporar à sua prática qualquer conteúdo, metodologia ou recurso educacional", que não tenham sido preparados em sua formação inicial ou continuada (FERNANDES, 2007).

Partindo dessa premissa, entendemos que Libras é a primeira língua dos surdos (L1) e deve funcionar como suporte para o desenvolvimento cognitivo e instrumento de interação. Já o português deve ser ensinado como segunda língua (L2) na modalidade escrita, visto que o domínio de uma língua escrita é parte da interação social do sujeito e esse aprendizado "permite a todos nós, ouvintes ou não, usufruirmos de uma cidadania plena" (REFERÊNCIA). Sendo assim, faz-se necessário "garantir a coexistência de sistemas linguísticos e culturais diferentes, sem relegar a um segundo plano a língua materna do nosso aluno surdo" (NOVAES, 2018, p.215).

Em se tratando do ensino-aprendizagem de surdos, um dado estatístico relevante a ser considerado é que mais de $90 \%$ das crianças surdas têm pais ouvintes que não conhecem nenhuma Língua de Sinais (LS) (EMMOREY, 2002; GOLDIN-MEADOW, 2003; MAYBERRY; EICHEN, 1991), o que faz com que a criança não tenha interação com uma língua efetiva desde a infância. Conforme os estudos de Skliar (1997a, p.128-129), "só 4\% ou 5\% das crianças

\footnotetext{
1 Cabe ressaltar que nesse artigo optaremos por utilizar o termo primeira língua ao invés de língua materna, por entendermos que a L1 é o primeiro idioma de um indivíduo e que necessariamente não precisa ser o idioma majoritário de um país. No caso dos surdos, a sua L1 será a Língua de Sinais, que é uma língua natural, de modalidade espaço-visual, já a segunda língua, de modalidade oral-auditiva, deverá ser ensinada aos surdos com ênfase na escrita.
} 
surdas - segundo as estatísticas internacionais - nascem e se desenvolvem em seus primeiros anos de vida dentro de uma família com pais surdos²". Assim, em sua maioria, quando os surdos vão para a escola, ainda não adquiriram uma língua, nem a de sinais, nem a língua utilizada pelos ouvintes, comunicam-se apenas por sinais caseiros $^{3}$. Só então é que vão aprender simultaneamente a LS e, aqui no Brasil, a LP na modalidade escrita.

A partir da Lei $10.436 / 02^{4}$ de 24 de abril de $2002^{5}$ e a sua regulamentação pelo Decreto 5.626 de 22 de dezembro de 2005, ocorreu um avanço na educação dos surdos, a Libras passou a ganhar mais visibilidade no país e trouxe o reconhecimento como meio legal de comunicação e expressão da comunidade surda brasileira. Nesse contexto, foi implantado, em Cuiabá, MT, o Centro Estadual de Atendimento e Apoio ao Deficiente Auditivo (CEAADA). Essa escola foi o primeiro Centro de Atendimento Educacional a crianças e jovens surdos da Capital mato-grossense, fundada no dia 20 de janeiro de 2000, e ainda é a única escola do Estado que oferece educação bilíngue, contemplando o ensino de Libras e de LP, e é também palco deste artigo.

Nesse sentido, este artigo tem por objetivo compreender o processo de apropriação de LP escrita como L2 para alunos surdos matriculados no oitavo ano do Ensino Fundamental no CEAADA. Em termos organizacionais, o artigo está dividido em quatro seções e subseções: sendo a primeira esta introdução, seguida da discussão sobre o processo de apropriação da escrita pelo surdo e a questão do Letramento e dos Gêneros Textuais no ensino da LP escrita para surdos. Em seguida, na terceira seção, será explicitada a metodologia de coleta de dados. Na quarta seção, têm-se as análises e a discussão dos dados, seguidas das considerações finais e referências bibliográficas.

\footnotetext{
2 Vale ressaltar que a aquisição de LS também pode se dar com pais ouvintes que aprenderam a LS para ensinar e se comunicar com o/a filho/a.

3 Forma de comunicação gestual desenvolvida por crianças surdas que carece de uma língua organizada para se comunicar com seus familiares que geralmente são ouvintes. Primeira forma de língua de sinais utilizada no seio familiar para comunicação no cotidiano. É uma "proto-língua" que carece de estruturação e sistematização. Pode ser entendida como baby talk ou motherese.

4

5 Lei que reconhece a Língua Brasileira de Sinais - Libras como meio legal de comunicação e dá outras providências.
} 


\section{A apropriação da escrita pelo surdo}

Até a década de 1980, o objetivo das escolas brasileiras para surdos era a oralização (PEREIRA, 2008), cujo pressuposto básico era a normalização dos surdos. A base de ensino seguia o modelo clínico-terapêutico, o qual vê o sujeito como um ser patológico. A surdez é vista como uma "deficiência" em relação à comunidade "ouvinte", colocando os sujeitos surdos em desvantagem, se comparados à maioria da população (SKLIAR, 1998). As práticas pedagógicas desse modelo tinham por objetivo reabilitar o indivíduo e eram denominadas de "ortopedia da fala" (SKLIAR, 1997a).

Seguindo essa mesma vertente mundial, no Brasil, desde a criação do primeiro espaço escolar para surdos, o INES, em 1897, a oralidade se manteve como a principal meta a ser atingida, "os surdos deveriam aprender a falar, ler e escrever a língua portuguesa através de diversas técnicas de correção do corpo, dos sinais e alfabeto manual" (SILVA, 2008, p.27). Todavia, a criação do Instituto também teve seu lado positivo, pelo fato de favorecer o encontro surdo-surdo possibilitando a construção da Libras, das culturas e identidades surdas, organizações políticas regionais e desportivas.

O império do oralismo, apoiado principalmente pelo desenvolvimento da medicina e da tecnologia, perdurou por muitas décadas; o ensino da LP oral obrigatória em nada alcançava a realidade dos surdos (SILVA, 2008). Devido à grande insatisfação com os resultados do oralismo, nos anos de 1970, uma nova filosofia definida como Comunicação Total passa a ser adotada, "a qual propõe o uso de gestos naturais, da língua de sinais, do alfabeto digital, da expressão facial, da fala e dos aparelhos de amplificação sonora para transmitir linguagem, vocabulário, conceitos e ideias" (GUARINELLO, 2007, p.31). Ainda que incluísse o uso de sinais, os objetivos permaneciam os mesmos: "a aquisição da fala e da escrita da língua oral majoritária" (SILVA, 2008, p.28).

Já no final da década de 1970, inicia-se um movimento de reivindicação pela língua e cultura das minorias linguísticas, sendo 
o surdo incluído nessas comunidades minoritárias que usam um idioma próprio, a LS. Conforme Guarinello (2007):

A partir daí, eles [surdos] passaram a reivindicar o direito de usar a língua de sinais como primeira língua (L1) e de aprender a língua majoritária como segunda língua (L2). Surge, então, a opção de uma abordagem bilíngue para os surdos, caracterizada pelo uso da língua de sinais da comunidade surda e pela língua da comunidade majoritária em momentos diferentes (GUARINELLO, 2007, p.32).

No Brasil, a visão colonialista em relação à língua começa a perder espaço no meio acadêmico a partir da década de 1990, quando foram realizadas algumas pesquisas sobre educação de surdos sob novas perspectivas (GESUELI, 1988; FERREIRA-BRITO, 1993; FERNANDES, 2003; GÓES, 1996; QUADROS, 1997; SKLIAR, 1998; PERLIN, 1998). "Pesquisas essas que passaram demonstrar a cientificidade da língua brasileira de sinais e seu inestimável valor na formação cultural, política e de identificação de cidadãos surdos" (SILVA, 2008, p.17).

Surge, então, a visão socioantropológica da surdez, na qual o sujeito passa a ser tratado como "surdo":

Para se referir àqueles que, independentemente do grau da perda auditiva, reconhecem-se como surdos, na medida em que valorizam a experiência visual e se apropriam da LS como meio de comunicação e expressão; reúnem-se com seus pares e partilham modos de ser, agir e pensar, bem como uma identidade cultural comum e um certo Deaf Pride, orgulho em ser surdo (RODRIGUES, 2008, p.61).

De acordo com Skliar (1997a), a adoção do bilinguismo é compatível com a concepção socioantropológica de sujeito surdo e de surdez, tal "abordagem tem como pressuposto básico de que o 
surdo deve adquirir como primeira língua a língua de sinais, considerada sua língua natural, e como segunda a língua oficial de seu país" (GUARINELLO, 2007, p.32), ainda segundo a autora:

A concepção socioantropológica sustenta que os surdos formam uma comunidade linguística minoritária, que utiliza e compartilha uma língua de sinais, valores, hábitos culturais e modos de socialização próprios. A comunidade surda, então, é aquela que utiliza a língua de sinais, possui identidade própria e se reconhece como diferente. A surdez passa, assim, a ser vista como diferença e não deficiência (GUARINELLO, 2007, p.32-33).

A partir de então, vários educadores brasileiros de surdos apropriaram-se dessa nova forma de pensar e propuseram estratégias de ensino utilizando a Libras e o português como L2. Esses vários autores passaram a investigar o processo de apropriação por alunos surdos de uma língua escrita que representa a modalidade oral-auditiva (ANDERSSON, 1994; AHLGREN, 1994; FERREIRA-BRITO, 1993; BERENT, 1996; QUADROS, 1997; entre outros) e apresentaram alguns aspectos fundamentais, conforme apontam Quadros e Schmiedt (2006, p.32-33):

(a) o processamento cognitivo espacial especializado dos surdos;

(b) o potencial das relações visuais estabelecidas pelos surdos;

(c) a possibilidade de transferência da língua de sinais para o português;

(d) as diferenças nas modalidades das línguas no processo educacional;

(e) as diferenças dos papéis sociais e acadêmicos cumpridos por cada língua;

( $f$ ) as diferenças entre as relações que a comunidade surda estabelece com a escrita tendo em vista sua cultura; 
(g) um sistema de escrita alfabética diferente do sistema de escrita das línguas de sinais;

(h) a existência do alfabeto manual que representa uma relação visual com as letras usadas na escrita do português.

Em suma, a exposição retardada e diminuída à linguagem que muitas crianças surdas experimentam pode impedir sua capacidade de aprender tarefas relacionadas à linguagem, incluindo a leitura, não apenas durante a infância, mas também durante a vida adulta (MORFORD; MAYBERRY, 2000). Sendo assim, os autores enfatizam que o crescimento contínuo de uma habilidade linguística, como a leitura, parece depender da aquisição da linguagem bem-sucedida e constante durante a primeira infância e o ensino fundamental. Portanto, conhecer um idioma, mesmo que seja sinalizado, com uma estrutura diferente da linguagem escrita, viabiliza muito mais a leitura do que não conhecer qualquer idioma.

Então, o primeiro passo para transformar crianças surdas em leitores proficientes é garantir que elas tenham uma língua.

Early detection of hearing loss, early entry into an educational system, and early and continuous contact with fluent signers together may go a long way toward ensuring that profoundly deaf children have access to and learn a language ${ }^{6}$ (GOLDIN-MEADOW; MAYBERRY, 2001, p.226).

Logo, o aprendizado da escrita e da leitura em uma L2 deve ser precedido da aquisição da L1 que será a base de todo o desenvolvimento cognitivo e social e, em se tratando de sujeito surdo, a sua L1 é a LS. Outro fato revelador é que crianças surdas não podem aprender uma primeira língua através da escrita. Segundo os autores, o aprendizado da L1 parece vir naturalmente para as crianças quando a língua é falada ou sinalizada, mas não quando é escrita. E um terceiro ensinamento é que as crianças precisam

$\overline{6 \text { A detecção precoce }}$ da perda auditiva, a entrada precoce em um sistema educacional e o contato precoce e contínuo com nativos fluentes podem garantir que crianças profundamente surdas tenham acesso e aprendam uma língua (tradução livre). 
ser ensinadas a ler. A leitura não vem naturalmente para todos os indivíduos que vivem em uma comunidade, portanto, ela deve ser ensinada (GOLDIN-MEADOW e MAYBERRY, 2001, p.227).

E o modelo de ensino que pode ser o mais apropriado é o da Educação bilíngue. A esse respeito, Guarinello (2007) justifica que a proposta bilíngue ainda é bastante recente em nosso país e que alguns projetos ainda estão em fase de implantação. Enquanto isso, Quadros (1997) confirma em seus estudos que algumas conquistas já foram alcançadas para que essa proposta seja colocada em prática:

o reconhecimento da pessoa surda enquanto cidadã integrante da comunidade surda com o direito de ter assegurada a aquisição da língua de sinais como primeira língua; o uso da língua de sinais na escola para garantir o desenvolvimento cognitivo e o ensino de conhecimentos gerais; o ensino da língua oral-auditiva com estratégias de ensino de segunda língua e a inclusão de pessoas surdas nos quadros funcionais das escolas (QUADROS, 1997. p.40).

Para tanto, Silva (2008) pondera que a Libras deve ser o meio de acessar as informações dos conteúdos da educação e da vida, enquanto a LP um meio de acessar a leitura e a escrita. Sendo assim, a Libras pode ser usada para compreender aspectos da LP, tanto quanto é utilizada para compreender quaisquer outros conteúdos. E recomenda:

Um ensino pautado numa filosofia bilíngue requer o estudo e observação de duas línguas que estão sendo usadas pelo indivíduo bilíngue e, sobretudo observar duas diferentes formas de organizar o pensamento. Além disso, ao oferecer um ensino bilíngue para surdos deve-se atentar para a questão de estarmos diante de duas línguas de modalidades diferentes, uma espaço-visual e outra oral-auditiva, e sendo os sujeitos de apren- 
dizagem não-usuários do canal auditivo, o ensino da língua oral deve ser oferecido a partir de visão de língua diferenciada (FERNANDES, 2005 apud SILVA, 2008, p.33).

Conforme Finau (2014), a valorização da modalidade escrita das LS ajudaria a diminuir a cristalização de organizações de estruturas de interlíngua nos textos desses alunos. A autora sugere que se avalie o papel da escrita da LS em um processo educacional de bilinguismo diglóssico, em que se reforça a necessidade de o sujeito adquirir uma LS primeiro, como a materna, e depois o sistema escrito da língua oral apenas para uso em situações socioculturais específicas.

É fundamental, portanto, viabilizar os saberes surdos, enxergálos como sujeitos e não como "deficientes", tratá-los como seres capazes, que leem o mundo com os olhos e não como aqueles que têm dificuldades de ler e escrever a língua oral majoritária. Silva (2008, p.20) recomenda que devemos reconhecer o sujeito surdo com as suas próprias características e não a partir de uma generalização conceitual e ressalta que apesar da questão do ensino-aprendizagem da LP ser um tema bastante discutido em estudos e pesquisas, ainda há muitas lacunas sobre metodologias que abranjam as perspectivas dos valores surdos (LS, escrita de sinais, artes surdas, pedagogia surda etc.).

Infelizmente, conforme aponta a autora, a apropriação da LP pelos surdos geralmente ocorre de forma sistemática, não-espontânea, num ambiente artificial por meio de metodologias de ensino que, na maioria das vezes, estão centradas em perspectivas de pessoas ouvintes e se valem de poucos recursos visuais.

Também não podemos comparar a aprendizagem de uma L2 por surdos a qualquer outra realidade de ouvintes aprendendo uma L2, já que há pelo menos quatro aspectos que os distinguem, conforme aponta Neves (2017, p.46), “(a) trata-se do aprendizado de uma segunda língua e modalidade; (b) o aprendizado é restrito à escrita; (c) pode haver diferentes contextos de aquisição da primeira língua e (d) a segunda língua é a língua majoritária do local 
onde vive". Para a pesquisadora, tais peculiaridades assinalam que o ensino da L2 para surdos depende de práticas compatíveis com as exigências inerentes ao aprendizado da escrita por esses indivíduos, de modo que a L1 desses sujeitos seja a base no ambiente escolar.

Para tentar modificar esse panorama, Neves (2017, p.52) apresenta algumas sugestões. Dentre elas, recomenda que o professor precisa planejar as suas aulas, isto é, selecionar textos "de verdade" e não recortes de um português que só existe na sala de aula, também enfatiza que é preciso dialogar com os textos imagéticos, contextualizar visualmente o texto, fazer com que eles compreendam e não somente automatizem o processo de leitura e escrita.

Ainda conforme a pesquisadora, é preciso acabar com o discurso do insucesso dos surdos no desenvolvimento do aprendizado da L2, é preciso ter em mente que, assim como os ouvintes, os surdos aprendem a ler e a escrever, contudo, os ouvintes aprendem numa modalidade escrita e têm como língua de instrução a sua língua materna, além de terem professores ouvintes, falantes dessa língua e com metodologias voltadas para o ensino de uma L1, enquanto que os surdos são estrangeiros na maioria das escolas do Brasil, já que a Libras é a sua L1 e não encontram no espaço escolar interlocutores dessa língua, que dirá aulas que considerem a Libras como língua de instrução no processo de ensino e aprendizagem da LP, na modalidade escrita (NEVES, 2017, p.52).

Essa postura de ensino precisa ser modificada, a Libras precisa ser efetivamente a mediadora de acesso ao conhecimento, inclusive como língua de base no aprendizado da LP, ou seja, a língua de instrução. Sem a Libras, o processo de aprendizagem da LP como L2 fica comprometido.

Muito embora os surdos não tenham tido a oportunidade de aprender a LS precocemente, é nela que a grande maioria se baseia para ler e escrever, nesse sentido, é imprescindível também que o surdo desenvolva uma língua efetiva, para tanto, é necessário que as experiências escolares oferecidas a ele privilegiem não apenas 
a LS, mas sobretudo os aspectos discursivos da escrita, uma vez que esses são "fundamentais para que o surdo se constitua como sujeito leitor e escritor, realizando um trabalho que proporcione a reflexão sobre o uso da linguagem escrita e da língua de sinais" (GUARINELLO, 2007, p.58).

Sendo assim, Guarinello (2007, p.59) sugere que a construção da linguagem escrita durante esse processo de aprendizado deva ser mediada por um adulto letrado, já que esse “orientará, mediará e atribuirá sentido à escrita das crianças. É por meio dessa construção conjunta de conhecimentos, do conhecimento de mundo e do conhecimento partilhado, que os textos fazem sentido para quem os lê."

É importante salientar que os surdos são usuários de uma língua distinta da maioria ouvinte, a Libras, e esse uso ainda não pode ser considerado equânime a todos os sujeitos surdos, que se apresentam em diferentes níveis de domínio e conhecimento. Conforme pondera Lodi et. al. (2015), muitos surdos não têm acesso a Libras e acabam desenvolvendo uma língua gestual caseira para fins de satisfação de necessidades e relatos de acontecimentos familiares e, quando esses mesmos sujeitos são expostos a Libras, não a diferenciam, inicialmente do português, "tratando-a como uma representação gestual da língua falada, fato que acarreta desvalorização da Libras por conceberem-na como uma língua de menor valor" (LODI et. al., 2015, p.13).

Uma tentativa para dirimir essa desvalorização da Libras, levantada pelas autoras, é investir em um sistema de registro escrito da Libras que possa contribuir para "estudos mais aprofundados das línguas de sinais por possibilitar uma análise descritiva dos elementos formacionais manuais e não manuais constitutivos da língua" (LODI et. al., 2015, p.14).

As autoras sugerem que a aprendizagem da escrita deve ser relativizada e pensada conforme as necessidades e particularidades de cada grupo social. Quanto aos surdos, elas defendem: 
acreditamos na importância da aprendizagem dessa língua [libras] e criticamos a forma pela qual ela vem sendo imposta a esses sujeitos: inferioriza-se e descaracteriza-se a língua de sinais e, consequentemente, a diferença linguística existente. Ignorando a diversidade de linguagens em circulação, pressupõese que, sem o domínio da escrita, conforme rege a norma culta, os surdos não terão condições de se desenvolverem completamente (LODI et. al., 2015, p.16).

Conforme as autoras, esse fenômeno não se restringe apenas à educação de surdos, mas também muito se aproxima daqueles observados com relação às comunidades indígenas. Elas ressaltam que descaracterizar ou não se assumir a língua dessas minorias como sendo suficientes para a compreensão e a aprendizagem das crianças, trata-se de uma questão de postura profissional (LODI et. al., 2015, p.17-18).

Para elas, a imersão social dos surdos e a ausência de registro escrito da LS acabam sendo fatores que dificultam o processo de resistência pela língua, e ponderam: “Embora, muitas vezes, aceite-se a língua de sinais como língua em circulação no ambiente escolar, ela é vista como prática de interação entre pares, para trocas de experiências cotidianas e informais, e não como língua em uso para as práticas de ensino" (LODI et. al., 2015, p.18). Nesse sentido, de acordo com as autoras, a Libras não é considerada como própria para o desenvolvimento e a apropriação dos conhecimentos veiculados social e culturalmente e nem tampouco para se ter acesso à LP. Importante destacar que esse cenário é muito comum nas escolas inclusivas, onde muitas vezes o professor regente utiliza apenas e tão somente a língua oral, e o ensino do surdo é intermediado pelo intérprete.

Concordando também com Lodi et. al. (2015, p.23), acreditamos que a Libras deve ser considerada e desenvolvida como primeira língua dos surdos e que as práticas educacionais para o ensino de segunda língua, ou língua estrangeira, sejam conhecidas, 
estudadas e aplicadas pelos educadores para o ensino do português escrito.

Uma das práticas adotadas para o ensino do português escrito é por meio de gêneros textuais. A concepção de gênero textual presente nos documentos oficiais brasileiros remete a Bakhtin, que disse:

Todos os diversos campos da atividade humana estão ligados ao uso da linguagem. Compreende-se perfeitamente que o caráter e as formas desse uso sejam tão multiformes quanto os campos da atividade humana, o que, é claro, não contradiz a unidade nacional de uma língua. O emprego da língua efetua-se em forma de enunciados (orais e escritos) concretos e únicos, proferidos pelos integrantes desse ou daquele campo da atividade humana (BAKTHIN, 2003, p.261).

Dessa forma, o gênero é produto das diversas interações humanas, produto da enunciação e da língua em uso. Para cada esfera sociocomunicativa, há gêneros que pertencem a ela ou são produzidos por ela. Temos que admitir que a visão de gênero tem sido tema de discussões entre estudiosos preocupados com o ensino da linguagem, entretanto, a institucionalização desse discurso no Brasil se consolidou a partir dos Parâmetros Curriculares Nacionais (PCNs), que veem no gênero textual um recurso de fundamental importância para a construção da cidadania do estudante:

Todo texto se organiza dentro de determinado gênero em função das intenções comunicativas, como parte das condições de produção dos discursos, as quais geram usos sociais que os determinam. Os gêneros são, portanto, determinados historicamente, constituindo formas relativamente estáveis de enunciados, disponíveis na cultura. São caracterizados por três elementos: conteúdo temático: o que é ou pode tornar-se dizível por meio do gênero; construção composicional: estrutura particular dos textos pertencentes ao gênero; estilo: configurações específicas 
das unidades de linguagem derivadas, sobretudo, da posição enunciativa do locutor; conjuntos particulares de sequências que compõem o texto etc. (BRASIL, 1998, p.21).

Essa noção de gênero refere-se, assim, a famílias de textos que compartilham características comuns, embora heterogêneas, como visão geral da ação à qual o texto se articula, tipo de suporte comunicativo, extensão, grau de literariedade, por exemplo, existindo em número quase ilimitado (BRASIL, 1998, p.22).

$\mathrm{Na}$ esteira do que foi proposto nos PCNs, na Nova Base Nacional Comum Curricular (BNCC), o texto ganha centralidade na definição dos conteúdos, habilidades e objetivos, considerado a partir de seu pertencimento a um gênero discursivo que circula em diferentes esferas/campos sociais de atividade/comunicação/ uso da linguagem.

Os conhecimentos sobre os gêneros, sobre os textos, sobre a língua, sobre a norma-padrão, sobre as diferentes linguagens (semioses) devem ser mobilizados em favor do desenvolvimento das capacidades de leitura, produção e tratamento das linguagens, que, por sua vez, devem estar a serviço da ampliação das possibilidades de participação em práticas de diferentes esferas/campos de atividades humanas (BRASIL, 2018, p.67).

Observam-se que essas recomendações tanto dos PCNs quanto da BNCC são condizentes em se tratando do ensino do português como L2 para surdos, haja vista que o professor de surdos deve incluir os mais variados textos como recurso didático, tanto para a atividade de leitura quanto de produção, com base nas situações reais de vida dos alunos, em enunciados que circulam no contexto da comunidade surda e da sociedade onde ela está inserida.

Pensando nisso, é que desenvolvemos quatro atividades priorizando uma diversidade de gêneros textuais, sejam elas: a fábula, crônica, história em quadrinhos e relato pessoal de rotina. Opta- 
mos por mesclar atividades que contemplassem a linguagem verbal e não verbal e estimulassem a produção, a criação e o pensamento crítico dos alunos.

\section{Metodologia da Coleta de Dados}

O presente trabalho ${ }^{7}$ foi operacionalizado mediante acompanhamento e participação de aulas ministradas de LP para aprendizes surdos matriculados no oitavo ano no CEAADA, constituindo uma pesquisa de cunho qualitativo do tipo estudo de caso e pesquisa-ação. Para esses sujeitos, foram propostas quatro atividades em LP, dentro da perspectiva dos gêneros textuais e práticas de letramentos, aplicadas em parceria entre a pesquisadora e a professora regente ao longo do ano letivo de 2019 para averiguar as produções textuais desses aprendizes, na tentativa de melhor compreender o processo de construção da escrita de uma segunda língua por esse público-alvo.

A aplicação das atividades seguiu as metodologias da Pesquisa-ação, em que o pesquisador constrói um ambiente de parceria e colaboração com os participantes, a sua inserção no grupo requer paciência, tolerância e honestidade durante todo o processo de aproximação e intervenção (BRANDÃO, 1999).

Bem como atentou para os métodos do Estudo de Caso que, conforme Yin (2001), é a melhor estratégia quando se quer responder qual a dificuldade de determinado grupo e por que isso acontece, de modo a considerar uma unidade social como um todo. Daí a justificativa de utilizarmos esse método para compreendermos quais as principais dificuldades desses alunos em relação à apropriação da LP como L2 e apontar estratégias para melhorar o processo de ensino-aprendizagem, atentando-se ao contexto escolar bilíngue.

7 Este estudo faz parte de uma pesquisa de Mestrado pelo Programa de Pós-graduação em Estudos de Linguagens - Mestrado/ IL/UFMT. 
Assim, foram desenvolvidas quatro atividades ancoradas na perspectiva dos Letramentos e Gêneros Textuais que contemplavam conteúdos e conhecimentos do $8^{\circ}$ ano do Ensino fundamental. As atividades foram a fábula, crônica, história em quadrinhos e relato pessoal de rotina. Procuramos sempre enfatizar a escrita em contextos significativos, nos quais a pessoa surda fosse capaz de interiorizar a LP e perceber a sua funcionalidade.

Cientes da importância da contextualização, antes de aplicarmos as atividades, provocávamos nos aprendizes o interesse pelo tema da leitura por meio de uma discussão prévia do assunto e de estímulo visual. Discutíamos também alguns elementos linguísticos presentes no texto, apresentávamos a proposta da atividade e juntas íamos desenvolvendo a atividade de forma colaborativa. Muitas vezes era a professora regente que explicava o andamento da atividade, em outro momento, eu assumia a explicação. Essa alternância me fez imergir em contatos mais profundos e me fez criar laços de confiança com os sujeitos da pesquisa, pois não estava apenas observando o andamento da aula, mas estava participando e contribuindo com o ensino dos aprendizes.

A geração de dados se efetivou através de análises de produções escritas em LP por aprendizes matriculados no oitavo ano do CEAADA, no município de Cuiabá-MT. Por se tratar de um “Centro Especializado", seguem as normativas da Portaria n 601/2018/GS/ SEDUC/MT, que dispõem sobre os critérios e procedimentos para a organização e funcionamentos de instituições semelhantes. A turma em que realizei a pesquisa era composta por 8 (oito) alunos matriculados, suas idades variam entre 14 e 16 anos. Todos os adolescentes são filhos de pais e mães ouvintes, apenas um deles tem uma tia surda, os demais não têm familiares surdos de primeiro grau. 


\section{A Apropriação da LP escrita pelos Aprendizes do Oitavo Ano do Ensino Fundamental do CEAADA-MT}

Neste estudo, guiamo-nos, inicialmente, pelas categorias propostas por Brochado (2003) ${ }^{8}$, para analisar a apropriação do português escrito pelos aprendizes do oitavo ano do Ensino Fundamental do CEAADA. No entanto, como são pesquisas e contextos diferentes, as categorias propostas e as que emergiram da análise de corpus diferem em alguns aspectos. Além disso, os eventos de letramentos são diferentes em cada escola brasileira, mesmo com um currículo unificador. Assim, consideramos também os eventos de letramentos criados e executados por nós como pesquisa-ação para analisar os dados revelados pelas atividades de escrita.

Intencionávamos analisar textos produzidos com base em gêneros propostos, porém, deparamo-nos com outra situação e entendemos que o local também constrói as experiências linguísticas dos aprendizes. Assim, com base nas amostras de produções escritas pelos sujeitos, adotamos as seguintes categorias para a análise:

\section{Em termos estruturais:}

1. Construções frasais;

2. Estrutura gramatical de frase;

3. Uso de palavras de conteúdo (substantivos, adjetivos, verbos);

4. Uso de determinantes (artigos, pronomes, numerais);

5. Uso de elementos de ligação textual (advérbio, conjunção, preposição);

6. Uso de pontuação;

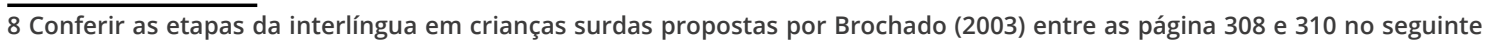
link: http://hdl.handle.net/11449/102476. 
7. Uso de letra maiúscula e minúscula;

8. Uso de verbos;

9. Emprego de verbos de ligação (ser, estar, ficar);

\section{Em termos de eventos de letramento:}

\section{Compreensão textual.}

Neste artigo, devido à sua extensão, focaremos nos três primeiros critérios ${ }^{9}$, a respeito dos quais iremos analisar e discorrer. É importante ressaltar que os enunciados dos sujeitos serão transcritos respeitando a exata forma de grafar escolhida pelo aprendiz, portanto podem aparecer em letra maiúscula ou minúscula.

A indicação dos interlocutores para designar cada informante será composta da letra $S$, que representa o sujeito, com o acréscimo de um número (Ex.: S1, S2, S3 e assim sucessivamente).

\subsection{Construções frasais}

A categoria de construções frasais refere-se à forma como sujeitos constroem as sentenças da língua ao utilizarem o código escrito. Desta feita, iniciamos a investigação observando a ordem das sentenças apresentadas pelos aprendizes, notamos uma preferência pelas construções simplificadas, enunciados curtos e objetivos, seguindo um princípio de otimização. É importante destacar que a escrita tem uma função utilitária na escola, por muitas vezes. O aluno escreve para responder ao professor, a exercícios e não porque quer registrar sua linguagem na forma escrita. De maneira geral, a escrita é uma modalidade de linguagem externa e precisa ser apropriada pelo aprendiz. Escreve-se quando se precisa escrever.

9 As análises foram suprimidas para serem inseridas neste artigo, porém podem ser conferidas por completo na dissertação intitulada "Apropriação da Língua Portuguesa escrita pelo surdo: um estudo de caso no CEAADA-MT" (AUTOR, 2021). 
Essa opção por construções frasais sintéticas foi observada em todas as atividades, a exemplo da primeira sobre a Fábula "A Arara e o Macaco". Essa atividade teve como objetivo observar as inferências dos aprendizes em relação à continuidade da história proposta. Intercalados aos fragmentos da Fábula apresentados aos sujeitos, fizemos alguns questionamentos a fim de analisarmos a coerência e a sequência lógica desenvolvida pelo aprendiz.

Em uma dessas perguntas, exigia-se que os aprendizes desenvolvessem um diálogo, pois foram questionados sobre "O que a arara e o macaco conversaram?", como resposta, obtivemos o seguinte:

\section{S1: Susto Ouvinte Medo Eles Correr Esconder \\ Casa Falar Acha Forar Leão Encontrar Ver Medo}

S2: leão Rugiu macaco medo

S3: pessoa leão ruguru ouvinte medo casa acho falar leão ver encontrar fui medo

S4: sustos que onça-Pintada Estavam escondida

S5: onça Pintada mal arara sim medo macaco medo sim

S6: onção rugiu eles andndo ouviram susto

medo rapido embora esconder

S7: onça Eu quer comer macaco

S8: vamos esconder

Ao retomarmos o quadro de Brochado (2003) sobre os estágios da IL, observamos que essa característica de predomínio de construções frasais sintéticas, por muitas vezes, de vocábulos soltos, como em S2, compreende a um atributo de quem ainda se encontra na IL1. Analisando outras respostas a essa mesma atividade, pudemos observar que os mesmos sujeitos que apresenta- 
ram respostas sucintas à questão acima, também o fizeram nas demais, entretanto, aqueles que desenvolveram respostas mais alongadas a essa questão, a fizeram com justaposição intensa de elementos da $L 1$ e da $L 2$, atributo que os enquadra na IL2, conforme a linguista.

Uma observação interessante a ser dita é que dois dos sujeitos chamaram os animais de ouvintes, uma vez que ouviram o rugido do leão, logo compreenderam que não se tratava de animais surdos. Essa observação nos mostrou a identificação do universo do surdo em relação ao universo letrado a seu redor. Contos, fábulas, crônicas fazem parte dos eventos de letramento de crianças, como histórias para ninar, ou narrativas representadas em desenhos animados, filmes, histórias em quadrinhos. O surdo, ao se deparar com esses universos, identifica quem faz parte da sua comunidade linguística e quem não faz. Nesse sentido, ressaltamos a importância da escola para oportunizar mais práticas de letramentos que representem a comunidade surda e demais comunidades, de forma que a visibilização destas comunidades torne-se cada vez mais presente.

Vejamos as respostas dos aprendizes à pergunta sequência da anterior "Qual foi a ideia do macaco?":

\section{S1: Leão ir Procurar Arara e o Macaco Ouvinte}

Sobre Entendi Forar Ver já Arara Macaco Embora

S2: Arara Briga Macaco

S3: A arara fugir leão ouvinte Procurar

\section{Então macaco ideia fugir}

S4: ideia fugir

S5: arara Briga macaco

S6: rapido fugir

S7: ideia arara fugir

S8: Briga 
A pergunta demandava que os sujeitos inferissem, pelo contexto, o que o macaco planejava. Podemos verificar que essas respostas foram ainda mais objetivas que as anteriores, contudo compreenderam que a arara e o macaco, como poderiam virar presas fáceis do leão, um animal muito superior a eles, encontraram uma solução para a situação: a fuga. Essa resposta quase unânime nos permite observar que os aprendizes estavam atentos à história, foram coerentes com a resposta e compreenderam a narrativa como gênero.

\subsection{Estrutura gramatical de frase}

Faz-se necessário salientar a forte influência da língua de sinais na produção escrita desses sujeitos, uma vez que eles partem da LS para chegar a compreensão da LP escrita. Também é importante deixar claro que a mistura de parâmetros da L1 e da L2 não é um fenômeno exclusivo dos escritores surdos. A condição de estranhamento do surdo em relação ao Português é semelhante ao que os ouvintes têm ao se depararem com uma língua estrangeira. A familiaridade maior é com a Libras, o que faz com que o aluno busque no significante dessa língua elementos para construir a escrita (PEIXOTO, 2006).

Através das respostas dos sujeitos à questão: "Alguém já ficou sozinho alguma vez? Já sentiu medo?", presente na Atividade 1, podemos verificar o emprego predominante de estrutura gramatical de frase muito semelhante à L1 e pouca característica da L2:

S1: Eu Medo Sim Sozinho Estou Rua
Noite Pessão Mal Perigo Hora Cuidado

S2: Nós casa medo nunca

S3: Eu medo sim sozinho Rua

está noite pessoa cuidado hora vamos 
S4: Estou casa medo nunca

S5: casa sozinho

S6: eu propria Sozinha coragem ir passear

Madrugada Noite conversar acabou

tchau eu ir casa

S7: Eu medo muito pessoas malvadas

S8: nunca

Entendemos que a pergunta motivadora também abria espaço para uma resposta simples, como sim ou não, apenas. E, mesmo assim, muitos sujeitos conseguiram expressar-se por meio de construções frasais que demonstram respostas completas, como em:

S3: Eu medo sim sozinho Rua.

Essa resposta aponta que sim, o sujeito se sentiu sozinho e que tem medo. Além de responder ao enunciado, ainda completou com a localização onde ocorre seu medo: Rua.

Esse exemplo, conforme Ferreira Brito (2010), comprova que, na Libras, não se usam artigos, preposições, conjunções, porque esses conectivos encontram-se incorporados ao sinal. No entanto, na LP, esses elementos são indispensáveis para a construção da coesão e coerência nos textos, responsáveis pelo sentido. Baseadas nessa afirmativa, é possível afirmar que a estrutura gramatical das frases dos aprendizes, mesmo se assemelhando mais com a da L1 do que à L2, está num processo de apropriação muito próximo à L2 no que tange ao sentido global do texto.

\subsection{Uso de palavras de conteúdo (substantivos, adjetivos, verbos);}

Observaram-se também que os itens lexicais mais utilizados na escrita dos surdos são os substantivos, adjetivos e verbos em 
detrimento das chamadas palavras funcionais. A despeito das escolhas lexicais, Beaugrande, 1997 (apud BROCHADO, 2003) se refere às palavras de conteúdo e às palavras funcionais:

\begin{abstract}
As palavras funcionais (por ex., os artigos, as preposições e as conjunções) - como os morfemas presos noutras línguas pertencem a conjuntos pequenos e fechados, tendo posiçõeschaves nas frases, mas tendo também significados esparsos e indeterminados. $\mathrm{O}$ 'trabalho lexical' é principalmente feito com as chamadas palavras de conteúdo (por ex., os substantivos, os verbos e os modificadores) os quais pertencem a grandes conjuntos abertos e têm posições flexíveis na frase, mas significados mais determinados e mais ricos. Uma palavra de conteúdo é mais autossuficiente e mais plausível de ser pronunciada isoladamente (por ex., 'fogo!', 'corra!', 'terrível!') do que uma palavra funcional (por ex., 'o', 'ao', 'ao invés', exceto quando se quer enfatizar um contraste (BEAUGRANDE, 1997, p.33, apud BROCHADO, 2003).
\end{abstract}

Nas respostas anteriores, essa prevalência já ficou explícita. Vejamos novamente exemplos desse predomínio de palavras de conteúdo através dos excertos a seguir retirados da atividade um, na qual estão marcados em vermelho os substantivos, em verde os verbos e em azul os artigos.

\title{
S1: Medo Macaco Arara Esconder Árvore
}

S2: Arara Briga macaco

S3: medo leão macaco A Arara Esconder

S4: ouvir onça ir encontrar

Onça mordr comer morreu

S5: arara Briga macaco

onça Encontrou Pegar Brigar

S6: onça ouviu briga encontrar morder

S7: morrer onça comer

S8: onça Procurou encontrou macaco Arara 
Nos exemplos apresentados, observa-se grande predomínio das palavras de conteúdo sobre as funcionais, o que Brochado (2003) afirma ser uma constante nas produções dos surdos. Isso nos revela que os sujeitos do estudo já dominam, em termos de vocabulário, grande parte dos nomes do seu mundo e aqueles mostrados nos textos. Dessa forma, para o ensino da LP e apropriação pelo sujeito surdo são necessárias aulas que demonstrem a funcionalidade na $L 2$ de elementos de coesão, como conectivos, de determinantes e outros elementos de conexão, como a pontuação.

\section{Considerações Finais}

É importante lembrar que os sujeitos deste estudo já estão nos Anos Finais do Ensino Fundamental, quando já deveriam dominar determinadas competências, quando deveria ser fortalecida a autonomia e assumido maior protagonismo em práticas de linguagem realizadas dentro e fora da escola. Como consequência do trabalho realizado em etapas anteriores de escolarização, os adolescentes já deveriam conhecer e fazer "uso de gêneros que circulam nos campos das práticas artístico-literárias, de estudo e pesquisa, jornalístico-midiático, de atuação na vida pública e campo da vida pessoal, cidadãs, investigativas" (BRASIL, 2018, p.136).

Entretanto, conforme pode ser observado pelas análises, muitas lacunas ainda não foram preenchidas e, assim como Silva (2005), acreditamos que "mudanças devem ser feitas na escola, principalmente se, em vez de falar em nome do outro, o professor caminhar ao seu lado, contribuindo para que esse outro possa se sentir seguro para se expor" (SILVA, 2005, p.40), o que não significa aceitar qualquer coisa como trabalho de escrita do surdo, muito pelo contrário, respeitar as suas particularidades enquanto um ser que vê na escrita um processo diferente dos ouvintes (GARCIA, 2012, p.73). 
Segundo Garcia (2012), os surdos jamais podem ser vistos dentro da escola pelos profissionais envolvidos em seu processo educacional como "corpos dóceis, indivíduos disciplinados, obedientes, que não questionam e que são submissos" (SCARPATO, 2006, p.73 apud GARCIA, 2012, p.73-74).

Qualquer concepção clínica ou tentativa pedagógica, cujos surdos forem vistos como corpos dóceis, fará desse projeto um sustentáculo ao ego ouvintista que, para o surdo, se houver, será de pouco significação. Ao contrário, se nos propusermos a considerar os direitos e as "potencialidades dos surdos", estaremos frente a um sujeito que se constituirá, na escola, como protagonista de sua cultura, de sua história (GARCIA, 2012, p.74).

E é exatamente isso que também almejamos, que os surdos se tornem autônomos e protagonistas de suas próprias histórias, e o caminho mais adequado para alcançar essa autonomia acreditamos que seja através da educação bilíngue, visto que ela proporciona um melhor desenvolvimento cognitivo, social e afetivo, bem como das práticas de letramento, fazendo com que o aprendiz compreenda e encontre sentido na aprendizagem da leitura e escrita, para utilizá-la no dia a dia de forma a atender às exigências que a própria sociedade impõe.

Em síntese, este artigo pretende contribuir para que as práticas de letramentos voltadas à comunidade surda se intensifiquem de forma que auxiliem na apropriação da escrita de português como educação bilíngue. Esse esforço colaborará para que esta comunidade seja participante ativa da comunidade que a cerca, na qual as práticas letradas assumem papel decisório no sucesso de crianças e adolescentes.

Ainda, avaliar a apropriação da escrita entre os sujeitos do oitavo ano no CEAADA fornece uma amostra do amplo processo de apropriação da escrita de LP pela comunidade surda, o que permite traçar estratégias pedagógicas de curto, médio e longo prazo para estes sujeitos. 
Por tudo isso, consideramos este artigo de extrema relevância, visto que pode contribuir para que os professores de LP para surdos compreendam melhor como se dá o processo de apropriação de LP escrita por surdos, saibam observar como o surdo constrói o texto escrito no ambiente escolar e percebam o quanto podem cooperar nesse processo. É importante salientar que as contribuições não se restringem apenas aos profissionais da Educação: nesse processo, investir em um ambiente familiar rico em eventos de letramento e proporcionar ao surdo o contato desde a mais tenra idade com usuários da Libras pode resultar em maior sucesso no desenvolvimento da aprendizagem da língua escrita.

\section{Referências Bibliográficas}

AHLGREN, I. Sign language as the first language. In: AHLGREN; HYLTENSTAM (Eds) Bilinguismindeaf education. Hamburg: SignumVerl, p. 15-36, 1994.

ANDERSSON, R. Second Language Literacy in Deaf Students. In Bilinguism in deaf education. Ahlgren \& Hyltenstam (eds.) Hamburg: Signum-Verl.. 91-102, 1994.

BAKHTIN, M. M. Estética da criação verbal. Tradução de Paulo Bezerra. São Paulo: Martins Fontes, 2003.

BERENT, G. P. The acquisition of english syntax by deaf learners. In Handbook of second language acquisition. Edited by William C. Ritchie \& Tej. Bhatia. Academic Press. San Diego: CA. 1996.

BRANDÃO, C. R. Pesquisa participante. São Paulo: Brasiliense, 1999.

BRASIL. Base Nacional Comum Curricular (BNCC). Brasília: MEC. 2018. Disponível em: http://basenacionalcomum.mec.gov.br/. Acesso em: 20 maio 2019.

BRASIL. Lei 10.436/02, de 24 de abril 2002. Dispõe sobre a Língua Brasileira de Sinais - LIBRAS e dá outras providências. Disponível em: http://www.planalto.gov.br/ccivil_03/leis/2002//10436.htm Acesso em: 27 jul. 2020. 
BRASIL. Decreto 5.626, de 22 de dezembro de 2005.

Regulamenta a Lei no 10.436, de 24 de abril de 2002, que dispõe sobre a Língua Brasileira de Sinais - Libras, e o art. 18 da Lei no 10.098, de 19 de dezembro de 2000. Disponível em: http:// www.planalto.gov.br/ccivil_03/_ato2004-2006/2005/decreto/ d5626.htm. Acesso em: 16 jun. 2017.

BRASIL. Parâmetros Curriculares Nacionais: Terceiro e Quarto Ciclos do Ensino Fundamental: Língua Portuguesa. Secretaria de Educação Fundamental. Brasília: MEC/SEF, 1998.

BROCHADO, S. M. D. A apropriação da escrita por crianças surdas usuárias da língua de sinais brasileira. 2003. Tese (Doutorado em Letras) - Universidade Estadual Júlio de Mesquita Filho, UNESP, São Paulo, 2003.

EMMOREY, K. Language, Cognition, and the Brain: insights from Sign Language Research. Londres: Lawrence Erlbaum Associates, 2002.

FERNANDES, S. Avaliação em Língua Portuguesa para alunos surdos: algumas considerações. 2007. (Desenvolvimento de material didático ou instrucional - TEXTO DIDÁTICO).

FERNANDES, S. Linguagem e surdez. Porto Alegre: Artmed, 2003. FERREIRA BRITO, L. Por uma gramática de língua de sinais. Rio de Janeiro: Tempo, 2010.

FERREIRA BRITO, L. Integração Social \& Educação de Surdos. Babel Editora. RJ. 1993.

FINAU, R. Aquisição de escrita por alunos surdos: a categoria aspectual como um exemplo do processo. Revista Brasileira de Linguística Aplicada, Brasília, v. 14, p. 935-956, 2014.

GARCIA, E. C. O que todo pedagogo precisa saber sobre Libras. Salto, SP: Schoba, 2012.

GESUELI, Z. M. A criança não-ouvinte e a aquisição da escrita. 1988. Dissertação (Mestrado em Linguística) - UNICAMP, Campinas, SP, 1988. GOLDIN-MEADOW, S. The resilience of language: what gesture creation in Deaf children can tell us about how all children learn language. Nova York: Psychology Press, 2003. 
GOLDIN-MEADOW, S.; MAYBERRY, R.I. How do profundly deaf children learn to read? Learning disabilities research \& practices, v. 16, 2001, p. 221-228.

GÓES, M.C.R. de. Linguagem, Surdez e Educação. Campinas, SP: Autores Associados, 1996.

GUARINELLO, A. C. O papel do outro na escrita de sujeitos surdos. 2. ed. São Paulo: Plexus, 2007.

LODI, A. C. B; MÉLO, A. D. B; FERNANDES, E. (Orgs.). Letramento, bilinguismo e educação de surdos. Porto Alegre: Mediação, 2015.

MATO GROSSO. PORTARIA N 601/2018/GS/SEDUC/MT. Dispõe sobre critérios e procedimentos para a organização e funcionamento dos Serviços da Educação Especial, nas Escolas e Centros Especializados e nas Escolas Comuns. Disponível em: diario_oficial_2018-10-25_completo (seduc.mt.gov.br). Acesso em: 20 jan 2020.

MAYBERRY, R.; EICHEN, E. “The Long-lasting Advantage of Learning Sing Language in Childhood: another look at the Critical Period for language acquisition." Jornal of Memory and Language, v. 30, 1991, p. 486-512. MORFORD, J. P.; MAYBERRY, R. I. (Eds.), Language acquisition by eye (p. 165-189). Lawrence Erlbaum Associates Publishers. 2000.

NEVES, B. C. Educação bilíngue para surdos e as implicações para o aprendizado da Língua Portuguesa como segunda língua. 2017. Tese (Doutorado em Linguística), UFSC, Florianópolis, 2017.

NOVAES, D. Q. A Produção de Textos dos alunos surdos na Universidade: Orientação e Avaliação. In: Letramento na diversidade: surdos aprendendo a ler/escrever. Ivani Rodrigues Silva; Marília P. Marinho Silva. (Orgs.). Campinas, SP: Mercado das Letras, 2018.

PEIXOTO, R. C. Algumas considerações sobre a interface entre a Língua Brasileira de Sinais (LIBRAS) e a Língua Portuguesa na construção inicial da escrita pela criança surda. Cad. CEDES vol.26 n.69 Campinas May/Aug., 2006.

PEREIRA, R. C. Surdez: aquisição de linguagem e inclusão social. Rio de Janeiro: Revinter, 2008. 
PERLIN, G. Identidades surdas. In: SKLIAR, C. (Org.) A surdez: um olhar sobre as diferenças. Porto Alegre: Mediação, 1998.

QUADROS, R. M. de. Educação de surdos: a aquisição da linguagem. Porto Alegre: Artes Médicas, 1997.

QUADROS, R. M. de; SCHMIEDT, Magali L. P. Ideias para ensinar português para alunos surdos. Brasília: MEC, SEESP, 2006.

RODRIGUES, C. H. Situações de incompreensão vivenciadas por professor ouvinte e alunos surdos em sala de aula: processos interpretativos e oportunidades de aprendizagem. 2008. Dissertação (Mestrado em Educação e Linguagem) - Belo Horizonte: Faculdade de Educação, Universidade Federal de Minas Gerais, 2008.

SILVA, C. M. O. O surdo na escola inclusiva aprendendo uma língua estrangeira (Inglês): um desafio para professores e alunos. 2005. 230f. Dissertação (Mestrado em Linguística Aplicada) - Universidade de Brasília, Brasília, 2005.

SILVA, S. G. L. da. Ensino de Língua Portuguesa para surdos: das Políticas as Práticas Pedagógicas. 2008. Dissertação (Mestrado em Educação) - UFSC, Florianópolis, 2008.

SKLIAR, C. B. Um olhar sobre nosso olhar acerca da surdez e as diferenças. In: SKLIAR, C. B. (Org.) A surdez: um olhar sobre as diferenças. Porto Alegre: Mediação, 1998.

SKLIAR, C. B. (Org.). Educação e exclusão: abordagens sócio-antropológicas em educação especial. Porto Alegre: Mediação, 1997a.

WFD - FEDERAÇÃO MUNDIAL DOS SURDOS. Documento de posicionamento relativo à Convenção das Nações Unidas sobre os Direitos das Pessoas com Deficiência, 2003. Disponível em: http://www.un.org/ esa/socdev/enable/rights/contrib-wfd.htm Acesso em: 20 de jul. 2020.

YIN, R. K. Estudo de Caso: planejamento e métodos. 2. ed. Porto Alegre: Bookman. 2001. 